\title{
Decision-Making in Adolescents According to Reaction Time, HEG and PASS
}

\author{
Frederic Pérez-Álvarez 1,2,3, Mireia Serra-Sala 1,3,4 and Carme Timoneda-Gallart 1,3,4 \\ ${ }^{1}$ Fundació Carme Vidal Neuro Psico Pedagogia Girona, Spain \\ ${ }^{2}$ NeuroPediatria/Neuro Conducta. Hospital Universitari Dr J Trueta Girona, Spain \\ ${ }^{3}$ Institut Recerca Qualitat de Vida Universitat de Girona, Spain \\ ${ }^{4}$ Facultat Educació i Psicologia Universitat de Girona, Spain
}

*Corresponding author: Álvarez FP, Neuropediatria/Neuroconducta, Fundació Carme Vidal Neuro Psico Pedagogia, University of Girona, Spain, Tel: +34972485291; E-mail: fpereza@comg.cat

Received: Oct 18, 2016; Accepted: Oct 25, 2016; Published: Oct 31, 2016

Citation: Perez-Alvarez F, Serra-Sala M, Timoneda-Gallart C. Decision-Making in Adolescents According to Reaction Time, HEG, and PASS. J Neurol Neurosci. 2016, 7:5.

\section{Abstract}

Background: The Planning, Attention, Simultaneous and Successive (PASS) theory of intelligence allows us cognitive assessment. Hemoencephalography (HEG) allows us to assess cortical prefrontal activity. Reaction time (RT) allows us to assess decision-making. We aim to find teenager profile according to the PASS, HEG, and RT.

Methods and findings: 59 secondary education adolescent students (30 females and 29 males, 14-16year-old, mean $=15.29, \mathrm{SD}=0.67$ ) were tested by two $\mathrm{RT}+$ HEG experiments. Stimuli of experiment 1 were cognitive and emotional dilemmas as displayed sentences or images. Stimuli of experiment 2 were shocking, unpleasant, and pleasant pictures with music or without music. PASS assessment was performed. We used oneway ANOVA (F-test) and correlation analysis. Longer reaction time was found in emotional dilemmas than cognitive items $(p=0.000)$. The HEG activity deviation from baseline was not consistent in both cognitive and emotional processing and the statistically significant value showed remarkable variability. HEG-activity differences at statistically significant level between cognitive and emotional processing were not found, indicating that both cognitive and emotional tasks scored close together. All this means atypical pattern related to adult pattern. Poorer planning, attention, and successive was associated with poorer academic performance $(p=0.00)$.

Conclusion: A longer RT in emotional decision-making along with a simultaneously atypical HEG activity and all this associated with the relationship between poorer planning and poorer academic performance makes it reasonable that an imbalance between cognition and emotion in adolescence (relative to adulthood) contributes to adolescent personality. This imbalance is hypothesized to result in distinct patterns of activity shown in $\mathrm{FMRI}$, and - we hypothesize - HEG in adolescence. Further HEG studies are needed.
Keywords: Adolescents; Development; Decision-making; Behavior; HEG; PASS

\section{Introduction}

Many studies have shown that adolescence is a characteristic period in development [1-16]. Many aspects of adolescence development remain poorly understood, particularly, in the field of cognitive-emotional interface. Research on how the brain develops, learns feels, makes decisions, and behaves is relevant for understanding adolescence.

Many neuroscience studies show remarkable consistency in the brain regions related to both cognitive and emotional processing. They are studies based on brain lesions [17-19], electrophysiological findings, particularly, Event-Related Potential (ERP) [20-22], but predominantly Magnetic Resonance Image (MRI) [23], Functional Magnetic Resonance Image (fMRI) [24-29], and Connectivity Functional Magnetic Resonance Image (cfMRI).

Within a neuroscience-related framework, how the brain expresses the mind is a key question [30-32]. A crucial argument is that we can differentiate two neurological networks: one responsible for cognitive processing (data information processing) and the other responsible for emotional-feeling processing as a sensitivity processing [33-40]. Evidence indicates that cognitive processing is supported by the younger external cortex, whereas emotionalfeeling processing is supported by the older internal cortex. Dorsolateral prefrontal (DLPC), parietal, occipital, and external temporal lobes are well-known parts of the cognitive network. The amygdala, insula, cingulated cortex, and medial inferior ventral prefrontal cortex are parts of the sensitive-emotionalfeeling network. Central processing of information includes the processing of cognitive information and feelings associated with it.

Unconscious processing becomes quite relevant within our conceptual framework. We assume that the response in a 
decision task is, first of all, unconsciously processed [31,32,41]. For example, after a child has performed a task, we can verify if the verbally reported strategy is indeed the one the child used, which we can deduce by observing, for instance, the eye movements of the child [30-33]. Frequently, we can see the verbal response is not corresponding to the strategy being used. We understand the verbalization is a posteriori mental process. First, central unconscious processing of beliefs/ knowledge takes place, and then verbalization arguing for the supposedly used strategy happens and it is elaborated at a later time (a posteriori). The brain initially creates a reasonable response by using its previously accumulated knowledge (knowledge base).

Intriguingly, this process is exactly what has been published in neuroimaging studies. One of them concludes: "our brain might cheat when learning or behaving. Instead of trying to answer a question by reasoning, our brain explores a catalog of previous answers to similar questions. The brain builds a repertoire of rote responses to frequently encountered problems that it can use as appropriate. This cheating mechanism also exists in people suffering from amnesia. This mechanism is highly efficient whether it is about learning or non-learning" by Dobbins et al. [26]. Similar information has been reported later [41]. In the same line of thought, another neuroimaging study by Soon et al. [27] tells us: "The outcome of a decision can be encoded in brain activity of prefrontal and parietal cortex up to 10 seconds before it enters awareness. This delay presumably reflects the operation of a network of high-level control areas that begin to prepare an upcoming decision long before it enters awareness." Similar conclusions have been reached through methods other than fMRI $[42,43]$. In line with previous thought, a recent investigation found that the response to stimuli was segmented into items separated by brief unconscious stops (about $200 \mathrm{~ms}$ ). These stops were decision processes or "moments of thought" that correlated with the difficulty of the decision [44].

The cognitive and emotional processing are constantly operating in parallel. The most surprising aspect is that countless different $\mathrm{fMRI}$ studies testing different symptoms such as stress, fear, anxiety, depression, and anger have identified the same brain areas. It is reasonable to identify this shared network with the fear-danger processing that is the base of self-confidence. Consistent with other studies, a own fMRI study identified the anterior and posterior cingulate cortex and the medial ventral prefrontal cortex, subserving emotional processing [28]. Recently, we have contributed to identify the two networks, external cognitive and internal emotional, using hemoencephalography (HEG) [16,45].

Excellent evidence from animal experiments [46] demonstrated that danger feeling is processed unconsciously and controlled by the amygdala, which triggers unconscious, uncontrolled, and automatic protective-defensive responses. This process also involves the prefrontal cortex that operates a posteriori. When danger is experienced (subconsciously much more often than consciously), the temporal amygdala sends out activation signals to the cognitive cortex as well as the somatic nervous system involved in the defense mechanisms.
The cognitive cortex is activated, and it puts into action the cognitive information processing (thought). What is produced by the cognitive cortex in this situation is based on the past experiences and sensory input from the environment in real time. This cognitive action happens in a posteriori time, which is why explanations may be considered justifications for the behavior. After the unconscious amygdale-related system has already decided on the behavior, the cognitive system comes up with the explanation. Likewise, we tend to explain what is happening to us by establishing cause-effect relationships with what are normally just triggering causal factors generally linked to what is entering through our senses in real time. Strikingly, this evidence is totally consistent with the previously mentioned neurofunctional evidence $[26,27]$.

The non-invasive in vivo $\mathrm{fMRI}$ is relevant in our research. The volumetric $M R I$ and $f M R I$ studies are revealing that the functional neural correlates of cognition-emotion interface change and mature at different rates during adolescent development compared with adults. Apart from MRI and fMRI, ERP has also contributed to expand our knowledge of the adolescent development. More will be said about this point throughout the discussion. For the moment, it will suffice to note that the evidence suggests continuing development across adolescence in the neural correlates of decisionmaking. In reviewing neuroscience literature, we find inconsistencies, which is a challenge to the interpretation of developmental findings. Bearing in mind these challenges, we will address these questions in order to contribute to clarify this issue.

Having constructed such a conceptual framework, we must remark many instruments used to assess cognitive-emotional interface require the subjective implication, and most importantly, studies based on auto-verbal-report remain difficult and in some points questionable, taking into account the explained unconscious processing. Many studies have been limited considerably by self-report techniques of questionable validity. Based on this premise, the idea of using Hemoencephalograpy (HEG) $[47,48]$ in this study of decisionmaking is supported by our previous reported studies $[16,45]$ using this instrument. The objectivity of a procedure like HEG has been also corroborated by other methods like ERP $[21,49]$ that was able to reveal that changes can be detected at the neural level earlier than at the behavioral level, and even P3 ERP might be a biomarker for academic achievement during childhood, independently of behavioral assessment [22].

We thus designed a decision-making experiment to measure cognitive-emotional interface supporting the internal decision process. The objective of the study was to relate reaction time (RT) to both cognitive and HEG assessment. At least, one study with this design, simultaneously using RT and P300 ERP has been so far reported [20]. The goal of this study was to better understand the patterns of RT, HEG activity, and PASS processing in adolescents to expand our data in the field coming from our previous research $[16,45]$.

We made some predictions. First, emotional tasks would process longer than cognitive tasks in RT tasks. Second, simultaneously obtained HEG activity would show atypical 
pattern according to our recent previous study [16], adolescents showing different pattern from adults. Third, PASS planning would be somehow related to emotional processing, taking into account the results in both RT and HEG activity. Finally, all the previous results would allow us to infer conclusions from the cognitive-emotional interaction in adolescents to explain decision-making and behavior.

\section{Material and Methods}

\section{Participants}

The sample was a group of 59 subjects ( 30 women and 29 men), teenage students (14-16 years old, mean=15.29, $\mathrm{SD}=0.67$ years) of fourth Compulsory Secondary Education, pertaining to secondary schools. Participants were recruited via direct contact with local schools.

Participants were recruited or excluded based on parent and educator report, consisting of self-report items assessing if they had a history of previous psychiatric o neurological disorder. All participants had normal vision, normal hearing, and spoke their native language. Each case was assessed by two blinded researchers, and inter-observer agreement of $80 \%$ was required. The questionnaire was completed by participants in school, and was posted to parents for completion. Data from academic achievement were informed by the school teachers. A medical screening was carried out to rule out any psychiatric or neurological illness. As needed, the following studies were carried out: ophthalmological exploration, otorrinolaringology exploration, videoelectroencephalography, somnography, both auditory and visual event-related potential, cardiological examination, and thyroid study. Subjects were excluded if they had any disease and/or medications.

Participants each assented to the study, and informed written consent was obtained from a parent/guardian. The study was approved by the local ethics committee (Fundació Carme Vidal).

\section{Experiment Design of Stimuli}

\section{Experiment 1}

Stimuli were clustered in blocks. Blocks 1, 2, and 3 included cognitive and emotional dilemma sentences. The response to each emotional dilemma implies to compare two choices. This has an emotional charge that is missing in the more rational cognitive response, whatever the emotional response. That is, a situation requiring a choice between equally undesirable alternatives. The emotional response implies to want to feel right in the sense of what is right and what is wrong as opposed to the rational response that is neutral. In total, 30 cognitive items, and 30 emotional items. We will expand on it later on in Procedure. Blocks 4, 5, and 6 included images concerning the consequences of the response to each stimulus in blocks 1, 2, and 3 respectively. Again, 30 cognitive tasks, and 30 emotional tasks. We will expand on it in Procedure.
Throughout the experiment, blocks 1, 2, and 3 were associated with HEG and RT recording. Blocks 4, 5, and 6 were logically associated with only $\mathrm{HEG}$ recording.

Example of cognitive sentence of block 1, 2, and 3 is as follows. "These two brothers you see on the screen are 6 and 8 years old. They have different hobbies. The short hair likes to play basketball and long hair likes the football. Sometimes they share hobby, but sometimes argue with each other because they do not agree on what to play. Tell me, the short hair likes to play football?"

Example of emotional dilemma sentence of block 1, 2, and 3 is as follows. "One night you are partying with your friends. You are happy. It is one o'clock, the time you have to return home according to your parents. Do you have a problem, bad if you stay and bad if you leave. You would like to continue the party, but your parents will get angry. Tell me what do you do?"

We intended to equate the mean (plus the range) word length and the number of clauses between conditions. Complete list of stimuli used are available from the authors upon request.

For blocks 4,5 and 6, stimuli were images displaying the consequence of the answer in corresponding blocks 1,2 , and 3. For instance, an image where the short hair plays basketball and the long hair plays football in the case of the cognitive example illustrated above. Concerning emotion sentence, an image where the parents are angry due to he/she decided not to come back home at the appointed time. Here, verbal answer was not required.

\section{Experiment 2}

The presentation contained three types of images: a first block (images 1-5), which showed five bloody images (accidents and mutilations), a second block (images 6-10), in which five smiling and friendly faces were displayed, and finally a third block (images 11-15), in which five photographs of very malnourished persons appeared. All of them are images of emotional processing with different sign (valence) and level of emotional impact. It is about a valence-based approach in the sense of the intrinsic attractiveness (positive valence) or aversiveness (negative valence), taking into account the International Affective Picture System. Details of the images are available from the authors on request.

\section{Measures}

\section{PASS/DN:CAS}

All subjects [ $n=59]$ were administered translated and validated for local population the DN: CAS (Das Naglieri Cognitive Assessment System) battery [33-36]. This battery assesses PASS processing, namely, Planning, Attention, Successive and Simultaneous. Tests of planning are: matching numbers, planned codes, and planned connections. Those of attention are: expressive attention, number detection, and receptive attention. Simultaneous tests are: nonverbal 
matrices, verbal-spatial relations, and figure memory. Successive ones are: word series, sentence repetition, sentence question (from 8 to 17 years) and successive speech rate (from ages 5 to 7 years). Each of the four PASS scales yields a standard score with a normative mean of 100 and a standard deviation (SD) of 15 . For three subtests in each of the four scales, the mean is 10 and the SD is 3.

Matching numbers requires children to devise a strategy to find and underline two numbers that are the same in a row. The numbers increase in length from one digit to seven digits. Planned codes show distinct set of codes and arrangements of rows and columns. A legend at the top of each page shows how letters correspond to simple codes (e. g., A, B, C, D correspond to $\mathrm{OX}, \mathrm{XX}, \mathrm{OO}, \mathrm{XO}$, respectively). Children must fill in the appropriate codes in empty boxes beneath each letter in any efficient manner (plan). Planned connections require children to efficiently connect numbers in sequence or numbers and letters in alternating orders. Expressive attention demands children to name the color of ink in the words, blue, yellow, green, and red that are printed according to Stroop phenomenon. Number detection consists of pages of numbers in different formats. Children are required to find, for instance, numbers 1,2 , and 3 on a page containing many distractors (e. g., the same number printed in different fonts). The child's performance is timed and it takes into account accuracy (correct minus false detections). Receptive attention demands the child identify letter pairs that meet specified criteria among many letter pairs that do not. Non-verbal matrices shows shapes and geometric designs that are interrelated through spatial or logical organization. Verbal-spatial relations shows drawings and a printed question; for instance, "which picture shows a circle to the left of a cross under a triangle above a square?" Figure memory requires the child to identify a geometric design when it is embedded in a complex figure. Word series demands the child to repeat words in the same order as stated by the examiner. Sentence repetition requires the child to repeat sentences, such as "the blue is yellowing" that are read aloud by the examiner.

Sentence questions (for those aged from 8 to 17 years) uses the same previous sentences, but in a different manner. Children have to read a sentence and are then asked a question about the sentence. For example, the sentence: "The blue is yellowing". The question: "who is yellowing?" The answer: "the blue." Successive speech rate requires the child to repeat a series of words in a particular linear order.

\section{HEG}

HEG (Biofeedback Institute, Los Angeles, CA) uses infrared light to measure the neuronal oxygenation through the skull, using the translucent property of the biological tissue for a wide range of wavelengths. The light goes right through the skin and skull to reach the neurological tissue located under the external sensor and returns Then, it is translated into values that are dependent on the perfusion and oxygenation of the underlying tissue. The values express the relationship between the variable absorption of infrared light and the nonvariable absorption of red light. The HEG headband has two optodes, a light generating LED pair and a sensor optode. An optode is red light $(660 \mathrm{~nm})$ and shines brightly when the power is on and the program is running. The other is invisible infrared $(850 \mathrm{~nm})$. The receptor optode is sensitive to the returning light. The optodes are placed in contact with skin on the Fp1 EEG point.

The effective penetration into the highly vascular cerebral cortical tissue is $\sim 1.50 \mathrm{~cm}$ below the midpoint between sensors covering an area of entry and exit of $0.052 \mathrm{~cm}^{2}$ on the surface of the skin. The emission of light penetrates, disperses, refracts and reflects. A small amount of light is returned to the surface and it is measured. The wavelength of red light (660 $\mathrm{nm}$ ) is less absorbed by the oxygenated hemoglobin than the deoxygenated hemoglobin. Infrared light $(850 \mathrm{~nm})$ is relatively unaffected by the degree of oxygenation of hemoglobin.

This technology is known as functional near-infrared spectroscopy (fNIRS). It operates very similarly to a pulse-oxymeter. It's an optical instrument, and works by measuring the color changes of the blood of the brain, taking into account the different color of oxygenated and de-oxygenated blood. That is, blood color translates into oxygen saturation. Oxygenated hemoglobin concentration, therefore, is useful in measuring local blood flow. A correlation exists between the blood flow in an area of the brain and the activity of the cells, a phenomenon known as "neurovascular coupling." Capillary oxygenation is based on the energy demand of tissues.

Specifically, the HEG uses lights of red and infrared low frequency. The light source and the light receiver (LED opted) are mounted on a headband separated from each other by 3 $\mathrm{cm}$. The device is designed to prevent interference of external light in measurements. The degree of muscle contraction does not affect the nirHEG measurement. Only $5 \%-10 \%$ of nirHEG readings come from the skin or cranial tissue. Reading is related to vascularization and blood volume in circulation.

The nirHEG ratio of the received waves is the base of the blood flow. The dependent variable is the changes in blood flow with changes in the oxygenated-deoxygenated hemoglobin ratio. The HEG device records this activity and translates it into conventional activity units that are used for comparisons in our study. Oxy-hemoglobin (Oxy-Hb) and deoxy- hemoglobin (deoxy-Hb) are not directly recorded. A higher value of activity translates to a higher level of blood flow that is considered an indirect indicator of neuronal activity.

A standardized basis for HEG ratio was established by Fp1 EEG point measurements in 154 adults. Direct scores were standardized; something similar to the standardization of a psychological test. The standard reference value was set to 100 $(S D=20)$ in order to calibrate all new spectrophotometers. Figure 1 shows the complete nirHEG equipment. 


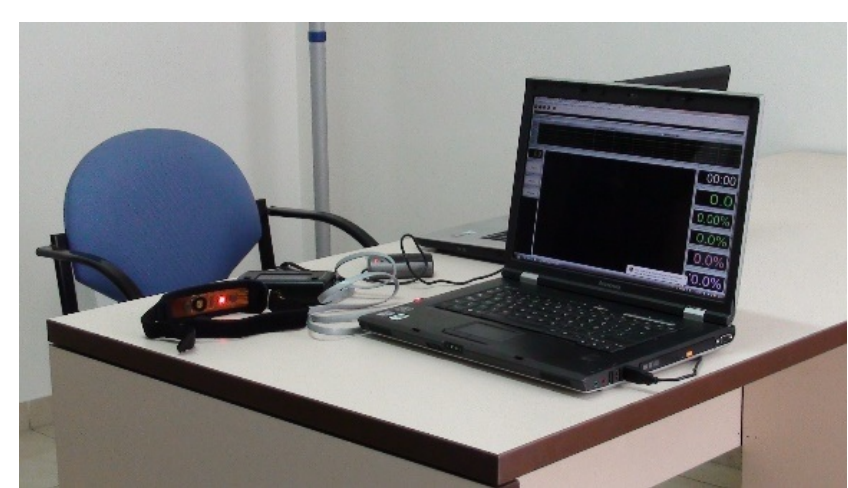

Figure 1 HEG instrument.

The display software provides the HEG ratio and also two other measures, the segment index HEG gain or improved percentage of HEG ratio so far, in the current session, and current index HEG gain, which is the immediate gain that varies every second. We used the current index HEG gain equivalent to the time in seconds the subject maintains the same level of oxygenation, and we report it in terms of HEG activity value.

\section{Reaction time}

Many experiments with RT have appeared in the literature on psychological studies. RT most typically is defined as the interval between the presentation of a stimulus to a subject and the subject's response. That is, it is the time needed for a subject to produce a response. Operationally, this interval can be measured from the end of the stimulus presentation to the initiation of the subject's response. That is the case in our study. For our purpose, we deal with the RT obtained as "decision time". The experimental task used to study the investigated question does not require a subject to make a correct versus incorrect response. That is why trial speed of responding is not emphasized in this case; caution on the part of the subjects and taking the amount of time necessary for a response is emphasized.

The procedure we are dealing with is much simpler and requires less practice and learning than other designs. For instance, it is not about an encoding stage needing long short term memory requirement or a comparison stage requirement to see whether or not the stimulus matched a set item. During the response, we obtained a continuous measure of HEG activity.

\section{Procedure-HEG + Reaction time}

\section{Experiment 1}

Stimuli were presented in blocks, namely, blocks 1 to 6 . Stimuli of blocks 1, 2, and 3, corresponding to reading sentences, were presented one after another by automated computer procedure such that each new successive sentence was presented as soon as RT response took place. Responses were verbal answer. Stimuli of block 1 were presented at 5 to 5 , successively, 5 cognitive were followed by 5 emotional sentences. Simultaneously, HEG and RT were recorded. Stimuli of blocks 4, 5, and 6, corresponding to images displaying the consequence derived from the response to each stimulus of blocks 1, 2, and 3 by each participant, were continuously presented one after another by automated computer procedure. Here, no response was needed; the response was in HEG recording. Again, stimuli of block 4 were presented at 5 to 5 , successively, 5 cognitive were followed by 5 emotional images.

HEG baseline condition was included in which subjects were asked to close his eyes and visualize the number 1 for a duration of 30s. For blocks 1,2, and 3, the instructions did not emphasize speed, but caution on the part of the subject and taking the amount of time necessary for a response. Care was taken to give identical instructions for each subject. The computer procedure was designed to trigger the next stimulus as soon as the response took place such that every 20 -second or 20-second-plus block stimulation was followed by 30 second period of no stimulation (rest period). The rest period is used to decorrelate the timing of stimulus onset with spontaneous hemodynamic oscillations in HEG. For blocks 4,5, and 6 , participants were presented with the image displaying the consequence derived from his/her response in blocks 1,2, and 3. Participants had $6 \mathrm{~s}$ to silently look at the image. After 6 $s$ of stimulation, the next stimulus was automatically presented. Every 18-second block of stimulation was followed by a 30 -second period of no stimulation (rest period). Again, the rest period is used to decorrelate the timing of stimulus onset with spontaneous hemodynamic oscillations in HEG.

\section{Experiment 2}

Different images were continuously presented one after another by automated computer procedure; 16-second block of stimulation followed by a 30-second period of no stimulation. The rest period is used to decorrelate the timing of stimulus onset with spontaneous hemodynamic oscillations. To minimize the cognitive requirement, we used a quasipassive viewing procedure, which reduces the linguistic cognitive component of the task to a minimum. Successively and alternatively, one participant performed the experiment with associated music, namely, Carmina Burana choral music, and another without associated music. Music is a source of pleasure or fear. According to the World Federation of Music Therapy, music is useful to optimize emotional, and intellectual well-being.

\section{Statistical Analysis}

We checked normal distribution adjustment by the ShapiroWilk test. We performed a univariate ANOVA entering task scores as the dependent variable on the whole sample $(\mathrm{N}=59)$. Using SPSS Version 22, differences were tested with F statistic, and the Pearson correlation coefficient analysis was computed where appropriate. 


\section{Results}

First of all, we present RT results. The RTs were averaged. The emotional item group $(\mathrm{N}=30$, mean $=2.44, \mathrm{SD}=0.62$, $\mathrm{SE}=0.11$ ) exhibited larger response compared with the cognitive item group $(\mathrm{N}=30$, mean $=1.28, \mathrm{SD}=0.1, \mathrm{SE}=0.02)$. The average values were submitted to one way analysis-of-variance (ANOVA), and the results revealed statistically significant effect, $F(1,58)=98,14, p=0.000$, indicating that the mean score was significantly longer for emotional group than for the cognitive group. Likewise, the Maximum RTs were averaged. The emotional item group $(\mathrm{N}=30$, mean $=5.87, \mathrm{SD}=1.25$, $\mathrm{SE}=0.22$ ) exhibited larger response compared with the cognitive item group ( $N=30$, mean $=2.43, S D=0.72, S E=0.13$ ). The average values were submitted to univariate ANOVA, and the results revealed statistically significant effect, $F$ $(1,58)=168.58, p=0.000$, indicating that the mean score was significantly longer for the emotional group than for the cognitive group. Table 1 reports the results of this analysis.

Table 1 One-way Anova Response time and Maximum time of response in emotional and cognitive items of blocks 1,2 and 3 $(\mathrm{N}=59)$.

\begin{tabular}{|c|c|c|c|c|c|c|c|c|c|c|}
\hline & \multicolumn{4}{|c|}{ Emotional items } & \multicolumn{4}{|c|}{ Cognitive items } & \multirow[b]{2}{*}{$F(1.59)$} & \multirow[b]{2}{*}{$\mathbf{P}$} \\
\hline & $\mathbf{n}$ & Mean & SD & SE & $\mathbf{n}$ & Mean & SD & SE & & \\
\hline Response Time & 30 & 2.44 & 0.62 & 0.11 & 30 & 1.28 & 0.13 & 0.02 & 98.14 & 0.000 \\
\hline Maximum Response Time & 30 & 5.87 & 1.25 & 0.22 & 30 & 2.43 & 0.72 & 0.13 & 168.51 & 0.000 \\
\hline
\end{tabular}

If we assume that the cognitive-emotional processes involved are not affected by extraneous variables, then the difference in the RT is independent of known confounding factors and can be interpreted as the duration of a mental processing.

Table 2 Difference in HEG activity during question time before response time comparing cognitive and emotional items of blocks 1,2 , and $3(\mathrm{~N}=59)$.

\begin{tabular}{|l|l|l|l|l|l|l|l|}
\hline \multicolumn{2}{|l|}{ Cognitive Items } & \multicolumn{2}{l|}{ Emotional Items } & \multicolumn{2}{l|}{} \\
\hline $\mathbf{N}$ & mean & SD & $\mathbf{n}$ & Mean & SD & F & P \\
\hline 30 & 617.69 & 13.88 & 30 & 619.32 & 9.56 & 0.277 & 0.061 (NS) \\
\hline
\end{tabular}

We analyzed the difference in mean HEG activity during question time before response time comparing cognitive and emotional tasks. There was not difference at statistically significant level, which means similarity in neurological activity between cognitive and emotional tasks during question time (Table 2).

Table 3 Correlations in cognitive and emotional items of Block 4.
Also, we investigated the homogeneous nature of both emotional tasks and cognitive task by using correlation analysis (Tables 3, 4 and 5).

\begin{tabular}{|c|c|c|c|c|c|c|c|c|c|c|c|c|c|c|}
\hline \multicolumn{15}{|c|}{ Cognitive Items } \\
\hline Items & 2 & 3 & 4 & 5 & 6 & 7 & 8 & 9 & 10 & 11 & 12 & 13 & 14 & 15 \\
\hline 1 & $0.61^{*}$ & NS & NS & $0.38^{*}$ & NS & NS & NS & NS & NS & NS & NS & NS & NS & NS \\
\hline 2 & - & $0.51^{*}$ & NS & NS & NS & NS & NS & NS & NS & NS & NS & NS & NS & NS \\
\hline 3 & - & - & $0.61^{*}$ & $0.31^{*}$ & NS & NS & NS & NS & NS & NS & NS & NS & NS & NS \\
\hline 4 & - & - & - & $0.71^{*}$ & NS & NS & $0.36^{*}$ & $0.27^{*}$ & $0.30^{*}$ & NS & $0.29^{*}$ & NS & NS & NS \\
\hline 5 & - & - & - & - & $0.35^{*}$ & NS & $0.27^{*}$ & NS & $0.30^{*}$ & NS & $0.38^{* *}$ & $0.29^{*}$ & NS & NS \\
\hline 6 & - & - & - & - & - & $\underset{*}{0.69^{*}}$ & $\underset{*}{0.44^{*}}$ & $0.29^{*}$ & $0.29^{*}$ & ${ }_{*}^{0.45^{*}}$ & NS & NS & NS & NS \\
\hline
\end{tabular}




\begin{tabular}{|c|c|c|c|c|c|c|c|c|c|c|c|c|c|c|}
\hline 7 & - & - & - & - & - & - & $\begin{array}{l}0.69^{*} \\
\text { * }\end{array}$ & $0.33^{*}$ & NS & $0.34^{*}$ & $0.31^{*}$ & $0.29^{*}$ & $0.27^{\star}$ & NS \\
\hline 8 & - & - & - & - & - & - & - & ${ }_{*}^{0.64^{*}}$ & NS & ${ }_{*}^{0.36^{*}}$ & $0.36^{\star *}$ & $0.40^{* *}$ & $0.30^{*}$ & NS \\
\hline 9 & - & - & - & - & - & - & - & - & $0.61^{*}$ & NS & NS & NS & $0.33^{*}$ & NS \\
\hline 10 & - & - & - & - & - & - & - & - & - & NS & NS & NS & NS & $0.33^{* *}$ \\
\hline 11 & - & - & - & - & - & - & - & - & - & - & $0.48^{\wedge \wedge}$ & NS & NS & $0.29^{*}$ \\
\hline 12 & - & - & - & - & - & - & - & - & - & - & - & $0.65^{* *}$ & NS & NS \\
\hline 13 & - & - & - & - & - & - & - & - & - & - & - & - & $0.60^{* *}$ & NS \\
\hline 14 & - & - & - & - & - & - & - & - & - & - & - & - & - & $0.56^{* *}$ \\
\hline \multicolumn{15}{|c|}{ Emotional Items } \\
\hline Items & 2 & 3 & 4 & 5 & 6 & 7 & 8 & 9 & 10 & 11 & 12 & 13 & 14 & 15 \\
\hline 1 & ${ }_{*}^{0.68^{*}}$ & $0.31^{*}$ & $\begin{array}{l}0.47^{*} \\
*\end{array}$ & $\begin{array}{l}0.52^{*} \\
\text { * }\end{array}$ & $0.32^{*}$ & NS & NS & NS & $0.28^{*}$ & NS & $0.29^{*}$ & $0.30^{*}$ & NS & NS \\
\hline 2 & - & $\begin{array}{l}0.75^{*} \\
*\end{array}$ & $\underset{*}{0.53^{*}}$ & $\underset{*}{0.56^{*}}$ & ${ }_{*}^{0.53^{*}}$ & $\begin{array}{l}0.52^{*} \\
*\end{array}$ & $\begin{array}{l}0.50^{*} \\
*\end{array}$ & $\begin{array}{l}0.45^{*} \\
*\end{array}$ & $\underset{*}{0.44^{*}}$ & $\underset{*}{0.35^{*}}$ & $0.40^{\star *}$ & $0.39^{* *}$ & $0.27^{*}$ & $0.39^{* *}$ \\
\hline 3 & - & - & $\begin{array}{l}0.67^{*} \\
\text { * }\end{array}$ & ${ }_{*}^{0.39^{*}}$ & $\begin{array}{l}0.46^{*} \\
*\end{array}$ & $\begin{array}{l}0.58^{*} \\
*\end{array}$ & $\begin{array}{l}0.58^{*} \\
*\end{array}$ & $\begin{array}{l}0.42^{*} \\
*\end{array}$ & $\begin{array}{l}0.27^{*} \\
\text { * }\end{array}$ & $\begin{array}{l}0.39^{*} \\
\text { * }\end{array}$ & $0.34^{\star *}$ & $0.36^{* *}$ & $0.28^{*}$ & $0.34^{* *}$ \\
\hline 4 & - & - & - & ${ }_{*}^{0.67^{*}}$ & ${ }_{*}^{0.45^{*}}$ & $\begin{array}{l}0.46^{*} \\
*\end{array}$ & $\begin{array}{l}0.44^{*} \\
\text { * }\end{array}$ & $\begin{array}{l}0.35^{*} \\
*\end{array}$ & NS & NS & NS & NS & NS & NS \\
\hline 5 & - & - & - & - & $l_{*}^{0.54^{*}}$ & $\begin{array}{l}0.47^{*} \\
*\end{array}$ & $\begin{array}{l}0.34^{*} \\
\end{array}$ & $0.32^{*}$ & $\begin{array}{l}0.44^{*} \\
*\end{array}$ & NS & NS & $0.28^{*}$ & $0.30^{*}$ & $0.40^{\star *}$ \\
\hline 6 & - & - & - & - & - & $\begin{array}{l}0.68^{*} \\
*\end{array}$ & $0.30^{*}$ & $0.29^{*}$ & $\begin{array}{l}0.39^{*} \\
*\end{array}$ & $\begin{array}{l}0.35^{*} \\
*\end{array}$ & NS & NSN & NS & $0.28^{*}$ \\
\hline 7 & - & - & - & - & - & - & $0.72^{*}$ & $\begin{array}{l}0.35^{*} \\
*\end{array}$ & $0.29^{*}$ & $0.30^{*}$ & $0.31^{*}$ & $0.30^{*}$ & $0.30^{*}$ & $0.46^{\star *}$ \\
\hline 8 & - & - & - & - & - & - & - & $0.67^{*}$ & NS & $0.28^{*}$ & $0.36^{\star *}$ & $0.40^{* *}$ & $0.40^{\star *}$ & $0.42^{\star *}$ \\
\hline 9 & - & - & - & - & - & - & - & - & $0.62^{*}$ & NS & NS & $0.28^{*}$ & $0.26^{\star}$ & $0.29^{*}$ \\
\hline 10 & - & - & - & - & - & - & - & - & - & NS & NS & NS & NS & NS \\
\hline 11 & - & - & - & - & - & - & - & - & - & - & $0.63^{\wedge \wedge}$ & $0.27^{*}$ & NS & NS \\
\hline 12 & - & - & - & - & - & - & - & - & - & - & - & $0.70^{\star *}$ & $0.42^{\star *}$ & $0.32^{*}$ \\
\hline 13 & - & - & - & - & - & - & - & - & - & - & - & - & $0.79^{* *}$ & $0.42^{* *}$ \\
\hline 14 & - & - & - & - & - & - & - & - & - & - & - & - & - & $0.61^{* *}$ \\
\hline
\end{tabular}

Table 4 Correlations in emotional dilemma items of Block 5.

\begin{tabular}{|c|c|c|c|c|c|c|c|c|c|c|c|c|c|c|}
\hline Items & 2 & 3 & 4 & 5 & 6 & 7 & 8 & 9 & 10 & 11 & 12 & 13 & 14 & 15 \\
\hline 1 & $0.78^{* *}$ & $0.40^{* *}$ & $0.32^{*}$ & $0.29^{*}$ & ${ }_{*}^{0.38^{*}}$ & ${ }_{*}^{0.46^{*}}$ & ${ }_{*}^{0.41^{*}}$ & ${ }_{*}^{0.38^{*}}$ & $\underset{*}{0.40^{*}}$ & NS & NS & ${ }_{*}^{0.35^{*}}$ & $\begin{array}{l}0.50^{*} \\
*\end{array}$ & $0.39^{* *}$ \\
\hline 2 & - & $0.69^{* *}$ & $\begin{array}{l}0.50^{*} \\
*\end{array}$ & $\begin{array}{l}0.48^{*} \\
*\end{array}$ & $\begin{array}{l}0.52^{*} \\
*\end{array}$ & $\begin{array}{l}0.53^{*} \\
*\end{array}$ & $\begin{array}{l}0.38^{*} \\
*\end{array}$ & $\begin{array}{l}0.46^{*} \\
*\end{array}$ & $\begin{array}{l}0.54^{*} \\
*\end{array}$ & NS & NS & $0.31^{*}$ & $\begin{array}{l}0.43^{\wedge} \\
\wedge\end{array}$ & $0.39^{* *}$ \\
\hline 3 & - & - & $\begin{array}{l}0.78^{*} \\
\text {. }\end{array}$ & $\begin{array}{l}0.46^{*} \\
*\end{array}$ & $\begin{array}{l}0.48^{*} \\
*\end{array}$ & $\begin{array}{l}0.43^{*} \\
*\end{array}$ & NS & $\underset{*}{0.40^{*}}$ & $\begin{array}{l}0.43^{*} \\
*\end{array}$ & NS & NS & $0.33^{*}$ & ${ }_{*}^{0.39 *}$ & $0.30^{*}$ \\
\hline 4 & - & - & - & ${ }_{*}^{0.75^{*}}$ & $\begin{array}{l}0.49^{*} \\
*\end{array}$ & $0.31^{*}$ & NS & $0.28^{*}$ & $0.32^{*}$ & NS & NS & $0.32^{*}$ & 0.31 & ${ }^{\wedge} \mathrm{NS}$ \\
\hline
\end{tabular}




\begin{tabular}{|c|c|c|c|c|c|c|c|c|c|c|c|c|c|c|}
\hline 5 & - & - & - & - & ${ }_{*}^{0.77^{*}}$ & ${ }_{*}^{0.35^{*}}$ & NS & $0.27^{*}$ & ${ }_{*}^{0.42^{*}}$ & $0.27^{*}$ & NS & NS & NS & NS \\
\hline 6 & - & - & - & - & - & $0.65^{*}$ & $0.31^{*}$ & $0.27^{*}$ & $0.57^{*}$ & $0.33^{*}$ & NS & $0.37^{*}$ & $\underset{*}{0.38^{*}}$ & $0.38^{* *}$ \\
\hline 7 & - & - & - & - & - & - & ${ }_{*}^{0.62^{*}}$ & $0.34^{*}$ & $\underset{*}{0.50^{*}}$ & NS & NS & $0.30^{*}$ & $0.48^{*}$ & $0.51^{* *}$ \\
\hline 8 & - & - & - & - & - & - & - & $0.75^{\star}$ & $0.44^{*}$ & $0.25^{*}$ & NS & NS & $0.32^{*}$ & $0.36^{* *}$ \\
\hline 9 & - & - & - & - & - & - & - & - & $0.57^{\star}$ & NS & $0.26^{*}$ & NS & NS & NS \\
\hline 10 & - & - & - & - & - & - & - & - & - & ${ }_{*}^{0.66^{*}}$ & $0.40^{*}$ & ${ }_{*}^{0.44^{*}}$ & $0.29^{*}$ & $0.31^{*}$ \\
\hline 11 & - & - & - & - & - & - & - & - & - & - & $0.76^{*}$ & $0.37^{*}$ & NS & NS \\
\hline 12 & - & - & - & - & - & - & - & - & - & - & - & $0.53^{*}$ & NS & NS \\
\hline 13 & - & - & - & - & - & - & - & - & - & - & - & - & $0.62^{*}$ & $0.36^{\star \star}$ \\
\hline 14 & - & - & - & - & - & - & - & - & - & - & - & - & - & $0.71^{* \star}$ \\
\hline
\end{tabular}

Table 5 Correlations in cognitive items of Block 6.

\begin{tabular}{|c|c|c|c|c|c|c|c|c|c|c|c|c|c|c|}
\hline Items & 2 & 3 & 4 & 5 & 6 & 7 & 8 & 9 & 10 & 11 & 12 & 13 & 14 & 15 \\
\hline 1 & $0.50^{* *}$ & NS & NS & $0.32^{*}$ & NS & $0.26^{*}$ & $0.29^{*}$ & $0.37^{* *}$ & $042^{* *}$ & $0.36^{* *}$ & $0.28^{*}$ & NS & NS & NS \\
\hline 2 & - & $0.67^{* *}$ & $0.29^{\star}$ & NS & NS & $0.29^{\star}$ & $0.30^{*}$ & $0.31^{*}$ & $0.31^{*}$ & NS & NS & NS & NS & NS \\
\hline 3 & - & - & $0.65^{\star *}$ & NS & NS & NS & $0.29^{*}$ & NS & NS & NS & NS & NS & NS & NS \\
\hline 4 & - & - & - & $0.55^{\star *}$ & NS & NS & $0.35^{\star *}$ & $0.30^{*}$ & NS & $0.28^{\wedge}$ & $0.43^{* *}$ & NS & NS & NS \\
\hline 5 & - & - & - & - & $0.58^{* *}$ & NS & NS & NS & NS & $0.35^{\star}$ & $0.47^{* *}$ & $0.35^{\star *}$ & NS & NS \\
\hline 6 & - & - & - & - & - & $0.66^{* *}$ & NS & NS & NS & $0.26^{*}$ & $0.35^{\star *}$ & $0.54^{* *}$ & $0.48^{* *}$ & $0.44^{* *}$ \\
\hline 7 & - & - & - & - & - & - & $0.66^{* *}$ & $0.27^{*}$ & NS & NS & NS & $0.40^{* *}$ & $0.33^{*}$ & $0.27^{\star}$ \\
\hline 8 & - & - & - & - & - & - & - & $0.69^{* *}$ & $0.38^{\star *}$ & $0.30^{*}$ & $0.26^{*}$ & NS & NS & NS \\
\hline 9 & - & - & - & - & - & - & - & - & $0.59^{* *}$ & $0.37^{* *}$ & $0.34^{*}$ & NS & NS & NS \\
\hline 10 & - & - & - & - & - & - & - & - & - & $0.75^{\star *}$ & $0.41^{* *}$ & $0.39^{* *}$ & NS & NS \\
\hline 11 & - & - & - & - & - & - & - & - & - & - & $0.63^{* *}$ & $0.36^{* *}$ & NS & NS \\
\hline 12 & - & - & - & - & - & - & - & - & - & - & - & $0.67^{* *}$ & $0.27^{*}$ & NS \\
\hline 13 & - & - & - & - & - & - & - & - & - & - & - & - & $0.61^{\text {** }}$ & $0.42^{* *}$ \\
\hline 14 & - & - & - & - & - & - & - & - & - & - & - & - & - & $0.82^{* *}$ \\
\hline
\end{tabular}

The result showed that the emotional tasks are more homogenous than cognitive tasks. Higher correlations are get in emotional tasks. Higher number of emotional tasks are correlated. We can infer that the emotional tasks are a homogenous phenomenon (feeling), but the cognitive tasks are a heterogeneous phenomenon instead.

Secondly, we present simultaneously obtained HEG activity results. Heterogeneous and somehow contradictory results were found in the sense that the premise coming from adult results that HEG emotional activity is associated with under HEG baseline and cognitive activity is above HEG baseline was not consistently found. Some cognitive scores were under baseline, some above baseline. Some difference in score was at statistically significant level, some was not. Likewise, with emotional scores. To clarify, all cognitive and emotional tasks of block 1 scored under baseline. Of all the aforementioned differences, some showed difference at statistically significant 
level, some did not. That is, the sign of deviation from baseline is not consistent in both cognitive and emotional processing and the level of statistically significant value shows remarkable variability. Furthermore, HEG-activity score difference at statistically significant level between cognitive and emotional processing was not found, indicating that both cognitive and emotional tasks scored close together (Figure 2).

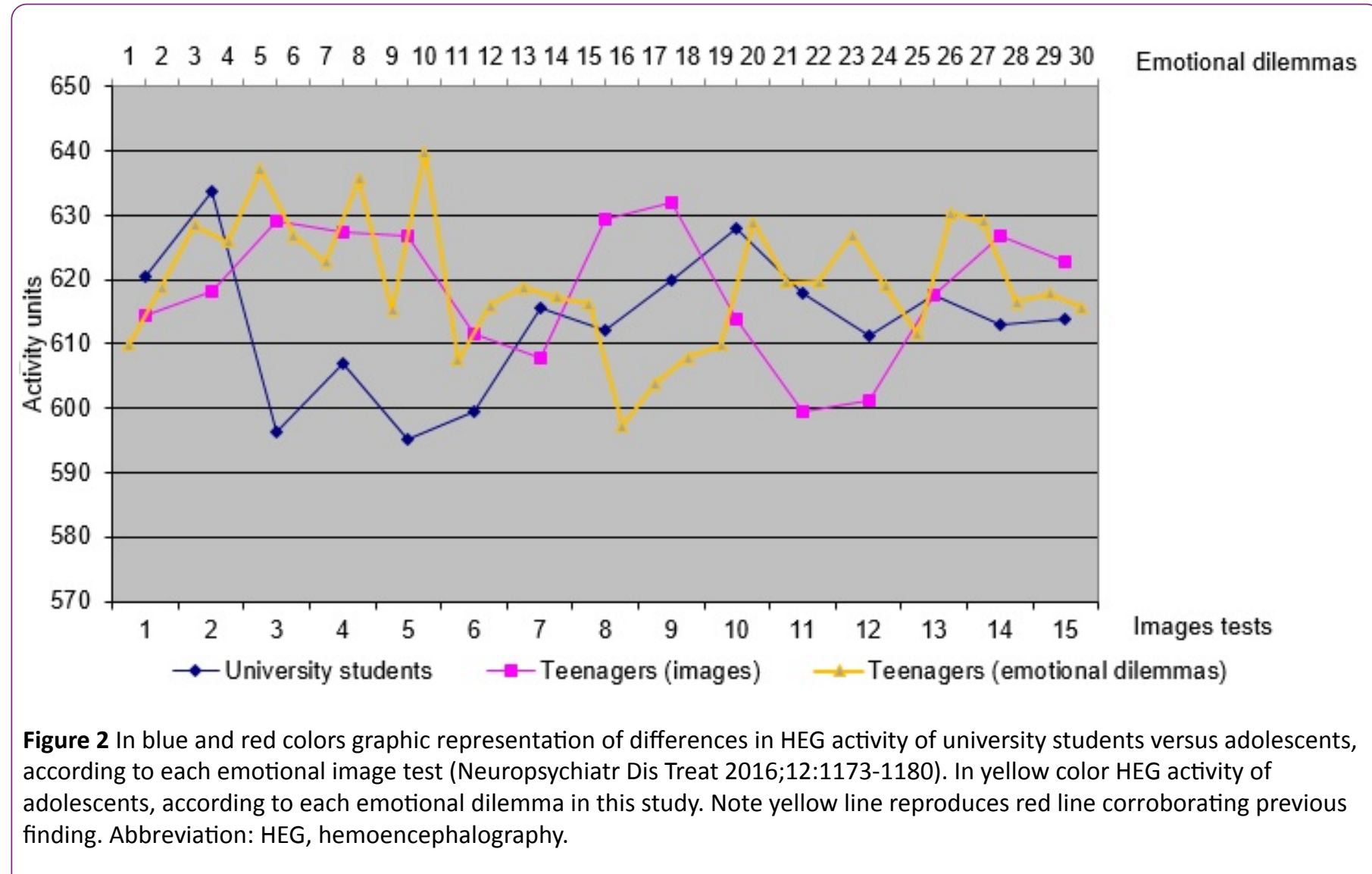

We must remember that scores higher than baseline are associated with cognitive external cortical regions. Lower scores are linked to internal cerebral regions. Although it will be discussed later, it seems that adolescents frequently processes cognitive and emotional tasks paradoxically, something like making fast decisions without consciously thinking or neglecting our gut feelings that tell us to choose a particular option.

We made two separate analyses, experiment 1 and experiment 2. All our results concern experiment 1 apart from what concerns to music results. Concerning experiment 2, we performed a comparison of HEG scores obtained in withmusic-task versus without-music-task. The HEG scores were averaged and comparison of scores between groups, withmusic-task versus without-music-task, was made. Only images 1 (shocking image), 12 (unpleasant image), and 14 (unpleasant image) showed statistically significant difference in HEG score. The image 1 atypically exhibited higher score in with-musictask $(\mathrm{N}=30$, mean $=626.84, \mathrm{SD}=45.31, \mathrm{ES}=8.27)$ compared with without-music-task ( $N=29$, mean $=601.66, \mathrm{SD}=44.72, \mathrm{ES}=8.30)$. The average values were submitted to one way ANOVA, and the results revealed statistically significant effect ( $F$ $(1,57)=4,61, p=0.03)$. The image 12 typically showed lower score in with-music-task $(\mathrm{N}=30$, mean $=583.58, \mathrm{SD}=57.27$, $\mathrm{SE}=10.45)$, as it would be expected according to adult pattern, compared with without-music-task $(\mathrm{N}=29$, mean=619.47,
$\mathrm{SD}=61.12, \mathrm{SE}=11.34)$. One way ANOVA revealed statistically significant effect $(F(1,57)=5,42, p=0.02$. The image 14 atypically showed higher score in with-music-task $(\mathrm{N}=30$, mean=640.08, SD=57.47, SE=10.49) compared with withoutmusic-task ( $\mathrm{N}=29$, mean=612.87, $\mathrm{SD}=46.47, \mathrm{SE}=8.62$ ). ANOVA revealed statistically significant effect $(F(1,57)=3.98, p=0.05)$. Apart from aforementioned images 1,12 , and 14, the rest of images exhibited atypical higher scores in with-music-task compared with without-music-task except in images 8, 9, and 11, where typical lower scores in with-music-task was observed. There were not differences at statistically significant level. We must remember that the typical adult pattern is lower score in with-music-task. Therefore, it's easy to see how the adult hypothesis can be disconfirmed in the majority of the images. Again, it seems that adolescents frequently processes cognitive and emotional tasks paradoxically, according to HEG adult pattern.

We can see that the HEG results are heterogeneous, but there is no reason to reject the hypothesis that the peculiar neurodevelopmental brain of the adolescents accounted for the observed effect (results). Strikingly, heterogeneous and inconsistent results must be paradoxically considered significant as will be discussed later. On the other hand, there is no reason to think in artifactual results. 
Finally, we present PASS score results. A comparison of PASS scores in failed and passed students of the sample was made. The passed students ( $\mathrm{N}=46$ ) showed higher scores in simultaneous ( $m e a n=99.00, S D=15.29, S E=2.25$ ), planning ( mean=93,98, SD=13.80, SE=2.03), attention ( mean=99.93, $\mathrm{SD}=15.45, \mathrm{SE}=2.03$ ), and successive ( mean=88.89, $\mathrm{SD}=12.14$, $\mathrm{SE}=1.79)$ compared with failed students $(\mathrm{N}=13)$ that showed lower simultaneous ( $m e a n=91.62, S D=11,63, S E=3,22$ ), planning (mean=80.46, SD=12.29, $S E=3.41$ ), attention ( mean=84,38, $S D=12,81, \quad S E=3.55$ ), and successive (mean=75.62, SD=13,82, SE=3.83). The average values were submitted to one way ANOVA, and the results revealed statistically significant effect for group in planning ( $F$ $(1,57)=10.15, p=0.002)$, attention $(F(1,57)=10,98, p=0.002)$, and successive $(F \quad(1,57)=11.40, p=0.001)$, but not in simultaneous $(F(1,57)=2.59, p=0.113)$, indicating that the mean score was significantly lower in planning, attention, and successive in failed students compared to passed students. There was statistically significant difference between groups as determined by ANOVA. Table 6 reports the results of this analysis.

Table 6 One-way Anova PASS processes for Passed and Failed students ( $N=59)$.

\begin{tabular}{|c|c|c|c|c|c|c|c|c|c|c|}
\hline \multirow[b]{2}{*}{ Cognitive Processes } & \multicolumn{4}{|c|}{ Passed } & \multicolumn{5}{|c|}{ Failed } & \multirow[b]{2}{*}{$\mathbf{P}$} \\
\hline & $\mathbf{n}$ & Mean & SD & SE & $\mathbf{n}$ & Mean & SD & SE & $F(1,58)$ & \\
\hline Simultaneous & 46 & 99 & 15.29 & 2.25 & 13 & 91.62 & 11.63 & 3.22 & 2.59 & 0.113 \\
\hline Plannig & 46 & 93.98 & 13.8 & 2.03 & 13 & 80.46 & 12.29 & 3.41 & 10.15 & 0.002 \\
\hline Attention & 46 & 99.93 & 15.45 & 2.03 & 13 & 84.38 & 12.81 & 3.55 & 10.98 & 0.002 \\
\hline Successive & 46 & 88.89 & 12.14 & 1.79 & 13 & 75.62 & 13.82 & 3.83 & 11.4 & 0.001 \\
\hline
\end{tabular}

On the other hand, no statistically significant relationship was found between PASS score and both HEG activity and RT. Differences are found, but they just do not quite reach an accepted level of significance.

\section{Discussion}

Basically, we tested three specific hypotheses and a corollary. First, emotional tasks would process longer than cognitive tasks in RT. Second, simultaneously obtained HEG activity would show atypical pattern in agreement with our previous study $[16,45]$ adolescents showing different pattern from adults. Third, PASS planning would be somehow related to emotional processing, taking into account results in both RT and HEG. Finally, all the previous results would allow us to infer conclusions to explain decision-making and behavior in the adolescents.

As for the first question, this study shows longer RT to respond to the emotional than cognitive tasks. As far as possible, we must rule out that the longer RT is not due to the longer cognitive processing in the emotional task than in cognitive task. The difference in mean HEG activity during question time before response time, comparing cognitive and emotional tasks, is not statistically significant, which means similarity in neurological activity (similarity in cognitive and emotional processing activity) (Table 3). A research on RT [50], applying the Subtraction Method, showed that there was no difference in RT for one- vs. three-syllable responses, concluding that the difference obtained in the experimental condition could not be attributed to the length in syllables of the stimulus word (cognitive load). In contrast, a clearly stronger correlation in emotional tasks than cognitive task (Tables 3, 4 and 5) means that emotional tasks are more homogenous than cognitive tasks, which can be interpreted in the sense that the emotional tasks involve a stronger common phenomenon than cognitive tasks. This common phenomenon can be reasonably attributed to emotional load that is more homogenous than cognitive load.

This finding objectively proves that emotional processing involves greater repercussion than cognitive does. It seems introspectively reasonable and tenable that the subject uses cognitive-emotional interaction and not only cognitive processing. We can make decisions without consciously thinking, but how we arrive at the decision is often a mystery. On the frame-work (introduction), we have argued on the "conscious versus unconscious mental evidence", which involves relatively recent novelty in the field of decisionmaking [26,27,30-33,41-44]. Thus, on the average, insecurity (emotion) will be associated with longer sequences of processing (by analogy, long RT) and security (confidence) with shorter sequences of processing. In a neuroimage study [29] the authors presented subjects between 10 and 17 years old morally simple scenarios, morally ambiguous scenarios, and not moral scenarios. In all ages trials with morally ambiguous situations activated prefrontal and parietal considerably more than simple moral judgments, suggesting that most neurocognitive processing is needed in this condition with higher emotional processing load. A ERP research [13] with adolescents aged 12 to 14 and college students measured the N2 ERP. Adolescents showed longer N2 amplitudes than adults for moral and neutral acts, but not for conventional acts (acceptable or unacceptable according to a certain rule).

With respect to the second point, this study shows that simultaneously obtained HEG activity shows atypical adolescent pattern in agreement with our recent previous study [45], adolescents showing paradoxical pattern different from adults (Figure 2). Adolescent atypical HEG pattern means a pattern different from adults. The adult HEG pattern was not consistently found and the results at statistically significant 
level were inconsistent. Analyzing the results of musical tasks in the parallel study, there was a high degree of concordance in the two sets of findings (experiment 1 and 2). Although not everyone experiences intense emotional responses to music and previous studies vary in the reported rates of these reactions [51-58], we think the music results corroborate the prediction of the hypothesis, that is, the adolescent central processing is different from adult processing, involving a dysfunction in the achievement of emotional and intellectual maturity. Adolescents frequently processes cognitive and emotional tasks paradoxically. The previously reported lower HEG activity decrease in emotional tasks in adolescents than expected according to adult results [45] has been replicated in this study (Figure 2). We assume this is a matter of controversy. Elucidating the exact meaning certainly requires more investigation.

These data converge with additional neuroscience evidence to support this analysis and interpretation based on dysfunctional maturity in adolescence. Age-associated changes lead to an improvement in learning, feeling, and behavior. Some contradictory results are found in different studies, reflecting the lack of a congruent synthetic theory. For instance, shared brain fMRI patterns appear linked to different tasks across different conditions, but here we can suggest a common meaningful explanation, independently of the task, that is, a common factor. One shared $\mathrm{FMRI}$ pattern involving ventral prefrontal cortex, anterior and posterior cingulated cortex and amygdale can be associated with the emotional processing linked to self-confidence.

Anatomical MRI, fMRI, cfMRI, and ERP studies have reported developmental differences between adolescence and adulthood, particularly, within regions of the cognitionemotion interface, subserving internal emotional network. Several regions turned out to be the most important, relevant ones, which were the bilateral amygdala, insula, cingulate, and ventromedial prefrontal cortex (MPFC), regions that are part of the broader limbic network. Although decrease in amygdale reactivity to emotional stimulus during adolescence has been described, we will focus our discussion on the cognitiveemotional interface that is represented by the DLPFC / MPFC (prefrontal cortex) interface. The MPFC continues to develop through the teenage years and it is associated with theory of mind or mentalizing.

Many $\mathrm{fMRI}$ studies have consistently showed that activity within anterior rostral MPFC, during mentalizing relative to control tasks, correlates negatively with age between adolescence and adulthood [4-5,8-9,59]. An fMRI mentalizing (thinking about intentions) study [2] in a total of 19 adolescent (aged 12.1-18.1 years), and 11 adults (aged 22.4-37.8 years), showed that part of the MPFC was significantly more active in teenagers than in adults. As you get older, MPFC activation decreases. This fact is associated with synaptic pruning phenomenon. In contrast, an fMRI study 11 investigated peer evaluation and rejection across age, in groups of preadolescent (8-10 years), young adolescent (12-14 years), adolescent (16-17 years) and adult (19-25 years) participants. The results showed an age-related increase in activity within ventral MPFC, anterior cingulate cortex and striatum. A contrasting result in this study is the age-related increase in ventral MPFC activity, while mentalizing studies show agerelated decrease in the more dorsally situated anterior rostral MPFC.

Two main age-associated changes have been described in volumetric MRI studies [8]. Firstly, cortical grey matter volume decreases across adolescence. Secondly, white matter volume increases across adolescence. Grey matter development takes place during adolescence in association regions (e.g. frontal and parietal lobes). Grey matter volume in the frontal (DLPFC and parts of MPFC) peaks around puberty onset in the frontal lobe (age 11 in girls and 12 in boys), and at around 16-17 years in the temporal lobe. These peaks in grey matter density decline throughout the remainder of adolescence and early adulthood (pruning). Pruning results in more finely tuned, robust and efficient neural circuits. An increase in the volume of white matter results in myelination with better axonal conduction speed and better inter-regional synchronization [8].

In sum, it is very important to make the point that an imbalance between cognition and emotion in adolescence (relative to adulthood) takes place, which can be associated with important changes in the MPFC. It is hypothesized that the emotional network with the amygdala attains functional maturity earlier in development than does the prefrontal cortex, and that the greatest mismatch in development of these systems occurs during adolescence [3]. Consequently, this mismatch can explain that individuals are more greatly affected by emotional context when making decisions [8]. This imbalance is hypothesized to result in distinct patterns of activity shown in fMRI studies, and - we hypothesize - HEG studies in adolescence.

The third point to discuss is PASS planning would be somehow related to the cognitive-emotional imbalance, taking into account that planning, selective attention, and successive are prefrontal-related processes [33-36]. We have analyzed the PASS variables in relationship to RT and HEG activity. There was no association at statistically significant level. However, we observed that all $(\mathrm{N}=59)$ planning scores were between the mean and -1SD/-2SD, that is, low scores. And the mean PASS score was significantly lower in planning, attention, and successive in failed students than passed students. There was a statistically significant difference between groups as determined by ANOVA (Table 6). Although no direct relationship between planning and RT and HEG was found, it is reasonable to relate planning to cognitive-emotional imbalance derived from RT and HEG results. Although primary planning dysfunction is possible, a planning dysfunction secondary to cognitive-emotional imbalance is quite more frequently found $[30,31-34,36]$. Therefore, we must link executive function to self-regulation, and, on the other hand, self-regulation to self-confidence. Executive function (planning + selective attention) is correlated with, and predictive of, academic achievement [60]. A dysfunctional planning may explain contradictory responses in a task. 
In what follows, we will show evidence of neuroscience for execute function (planning + selective attention), working memory (successive), and self-regulation and self-confidence in adolescence (development). In a study [12] the authors scanned 12- year-olds and young adults before and after 6 weeks of practice. Adults engaged the lateral fronto-parietal network more strongly. By contrast, 12-year-olds did not make good use of this working memory network for the more demanding task until the second time they were scanned, after 6 weeks of practice. Thus, adolescents needed 6 weeks of practice to approach the task more like adults, thereby emphasizing the role of age-related experience in development [61].

It is hypothesized that greater top-down/down-top interaction results from developing connectivity between DLPF-MPFC. It is assumed that executive function has a major contribution to the development of moral [15]. Adults and infants reason differently about moral (greater emotional load) and conventional acts (lower emotional load) [15,29,62]. Adolescent behavioral research has shown links between executive function and moral judgments. It has been showed [9] continuing development during late adolescence (between age 17 and early adulthood) in performance on mentalizing trials, relative to rule-based control trials relying on executive functions only. It points to neural circuits associated with executive function, that is, DLPF-MPFC interaction.

Decision-making is associated with confidence, and confidence guides decisions [63,64]. The more you are unconfident, the less planning you use $[30-34,40]$. Selfconfidence is inherently linked to self-identity [5,64]. A study in a sample of adolescents and adults (aged between 11 and 41 years) indicated that confident judgments ability improves across the period of adolescence, is highest in late adolescence and stabilizes in adulthood [14]. It has been also reported that confidence judgments improve during late childhood, age 7-12 years [65]. Several studies have reported that adults are better than adolescents in the control of action [14], in self-evaluation, [6] and top-down control [66]. An implicit system of conflict and error monitoring is considered to be supported by the posterior MPFC [67]. But also dorsolateral prefrontal and anterior cingulated cortex in response to feedback have been involved in 13-16-year-olds [68], and gray matter volume of Brodmann area 10 has showed to correlate positively with metacognitive ability [10].

The developmental cognitive-emotional neuroscience research may have implications for health across adolescence and adulthood $[69,70]$. Disability in regulation (modulation) of emotional response to negative emotional stimuli (fear and insecurity) in adolescence may be an indicator of possible future clinical and psychiatric disorders. HEG pattern might be a useful marker to define maturation and future possible mental dysfunctions. Research suggests that adolescence is a key time for the development of the cognitive-emotional interface and self-confidence. Little is yet known about the relationship between self-confidence and behavior at neurological level $[69,70]$.
A number of limitations have been found in this study, such as the low number of participants. A larger sample of participants might be more reliable to generalize the results to a larger population. We assume that the results on HEG are a matter of controversy. Future studies should disentangle the nature of these results, and the generalization of these results to other tasks with varying cognitive-emotional loads. Another point is that some association at statistically significant level between PASS scores and RT-HEG activity would have been desirable to reinforce the cognitive-emotional interrelationship. Future studies with larger sample size might be informative in this respect. Finally, a design with enough follow-up would allow us to verify the age-related changes in HEG activity, and on the other hand, to find patterns in HEG activity predictor of learning and behavioral dysfunctions and even psychiatric disorders.

\section{Conclusion}

Our finding that RT is longer in emotional decision-making along with a corroborated atypical simultaneous HEG activity response, suggesting maturation dysfunction, and also all this associated with the relationship between planning and academic performance makes it reasonable that our findings are consistent with what's been hypothesized.

RT, HEG, and PASS have been used to study information processing in adolescent sample to discuss decision-making phenomenon. A design based on an innovative neurosciencerelated framework has allows us to conclude ideas that are consistent and convincing to explain decision-making in adolescents. This study seems to corroborate that decisionmaking in adolescents is different from adult. HEG might be a biomarker for academic achievement during childhood, independently of behavioral assessment $[69,70]$. This study expands HEG research on attention deficit hyperactive disorder [71,72], dyslexia [73], autistic spectrum disorder [74], traumatic brain injury [74], migraine [75], and depression and anxiety [75] where HEG has proved to be useful for both diagnosis and treatment.

As a corollary, this study has contributed to emphasize that the collaboration between neuroscience, psychology, primary care medicine and education contributes to a better understanding of learning, feeling, and behavior. Obviously caution is needed in interpreting our results. Although the results of the study are promising, it is still necessary to continue accumulating evidence that allows us to find out exactly which type of pattern is appropriate to improve which specific aspects within the cognition-emotion interface. HEG analysis is non-invasive, painless, and cheap in order to investigate and reach clinical applicability in a near future.

\section{Acknowledgments}

The authors acknowledge the individuals who participated in this study. They express their deepest appreciation to the subjects and families who provided the possibility to complete this study. Also, to all professionals who contributed to this study in any way, such as statistical analysis, computational 
assistance, suggestions, comments, and encouragement. A special thanks goes to our team mates, Jordi Baus, Jordi Hernández, Oscar Mateu, Tomy Muñoz, Anna Orri, and Martí Ribas. Last but not least, many thanks go to Hershel Toomim, pioneer of the HEG.

\section{Author Contributions}

All authors contributed toward data analysis, drafting and critically revising the paper and agree to be accountable for all aspects of the work. M Serra-Sala ran all data-collection procedures. They all approved the final version of the manuscript for submission and agreed to be accountable for all aspects of the work.

\section{Disclosure}

The authors report no conflicts of interest in this work.

\section{References}

1. Nelson EE, Leibenluft E, McClure EB, Pine DS (2005) The social re-orientation of adolescence: a neuroscience perspective on the process and its relation to psychopathology. Psychol Med 35:163-174.

2. Blakemore SJ, Den Ouden H, Choudhury S, Frith C (2007) Adolescent development of the neural circuitry for thinking about intentions. Soc Cogn Affect Neurosci 2: 130-139.

3. Casey B, Jones RM, Hare TA (2008) The adolescent brain. Ann N Y Acad Sci 1124: 111-126.

4. Blakemore SJ (2008) The social brain in adolescence. Nat Rev Neurosci 9: 267-277.

5. Sebastian C, Burnett S, Blakemore SJ (2008) Development of the self-concept during adolescence. Trends Cogn Sci 12: 441-446.

6. Demetriou A, Bakracevic K (2009) Reasoning and self-awareness from adolescence to middle age: Organization and development as a function of education. Learn Individ Differ 19: 181-194.

7. Blakemore SJ (2015) The developing social brain: implications for education. Neuron. 25: 744-747.

8. Burnett S, Sebastian C, Kadoshc KC, Blakemore SJ (2011) The social brain in adolescence: Evidence from functional magnetic resonance imaging and behavioral studies. Neurosci Biobehav Rev 35: 1654-1664.

9. Dumontheil I, Apperly IA, Blakemore SJ (2010) Online usage of theory of mind continues to develop in late adolescence. Dev Sci 13: $331-338$

10. Giedd JN, Rapoport JL (2010) Structural MRI of pediatric brain development: What have we learned and where are we going? Neuron 67: 728-734.

11. Gunther Moor B, Van Leijenhorst L, Rombouts SARB, Crone EA, Van der Molen MW (2010) Do you like me? Neural correlates of social evaluation and developmental trajectories. Soc Neurosci 23: 1-22.

12. Jolles DD, Van Buchem MA, Rombouts SA, Crone EA (2012) Practice effects in the developing brain: a pilot study. Dev Cogn Neurosci 2: S180-S191.
13. Lahat A, Helwig CC, Zelazo PP (2013) An ERP study of adolescents and young adults judgments of moral and social conventional violations. Child D evelopment 84: 955969.

14. Weil LG, Fleming SM, Dumontheil I, Kilford EJ, Weil RS, et al. (2013) The development of metacognitive ability in adolescence. Conscious Cogn 22: 264-271.

15. Lahat A (2015) The neurocognitive development of moral judgments: The role of executive function. In: Decety J \& Wheatley T, (eds). Moral Brain. A multidisciplinary perspective. Cambridge, Massachussetts, London England: The MIT Press 143-156.

16. Serra-Sala M, Timoneda-Gallart C, Pérez-Álvarez F (2016) Clinical usefulness of hemoencephalography beyond the neurofeedback. Neuropsychiatr Dis Treat 12: 1173-1180.

17. Damasio AR (1994) Descartes' error. New York: Putnam.

18. Damasio AR (1999) The feeling of what happens: Body and emotion in the making of consciousness. San Diego: Harcourt.

19. Camille N, Coricelli G, Sallet J, Pradat-Diehl P, Duhamel JR, et al. (2004) The involvement of the orbitofrontal cortex in the experience of regret. Science 304: 1167-1170.

20. McCarthy GE, Donchin E (1981) A metric for thought: a comparison of P300 latency and reaction time. Science 211: 77-80.

21. Espinet SD, Anderson JE, Zelazo PD (2012) N2 amplitude as a neural marker of executive function in young children: an ERP study of children who switch versus perseverate on the Dimensional Change Card Sort. Dev Cogn Neurosci 2: S49-S58.

22. Hillman $\mathrm{CH}$, Pontifex MB, Motl RW, O'Leary $\mathrm{KC}$, Johnson $\mathrm{CR}$, et al. (2012) Academic achievement, scholastic performance, P3, inhibition, working memory, executive control. Dev Cogn Neurosci 2: S90-S98.

23. Ameis SH, Lerch JP, Taylor MJ, Lee W, Viviano JD, et al. (2016) A diffusion tensor imaging study in children with ADHD, Autism Spectrum Disorder, OCD, and matched controls: Distinct and non-distinct white matter disruption and dimensional brainbehavior relationships. Am J Psychiatry

24. Raichle ME (1998) Behind the scenes of functional brain imaging: A historical and physiological perspective. Proc Natl Acad Sci USA 95: 765-772.

25. Cabeza R, Nyberg L (2000) Imaging cognition II: An empirical review of 275 PET and fMRI studies. J Cogn Neurosci 12: 1-47.

26. Dobbins IG, Schnyer DM, Verfaellie M, Schacter DL (2004) Cortical activity reductions during repetition priming can result from rapid response learning. Nature 428: 316-319.

27. Soon CS, Brass M, Heinze HJ, Haynes JD (2008) Unconscious determinants of free decisions in the human brain. Nat Neurosci 11: $543-545$

28. Pujol J, Reixach J, Harrison BJ, Timoneda C, Vilanova JC, et al. (2008) Posterior cingulate activation during moral dilemmas. Hum Brain Mapp 29: 910-921.

29. Eslinger PJ, RobinsonLong M, Realmuto J, Moll J, de OliveiraSouza R, et al. (2009) Developmental frontal lobe imaging in moral judgment: Arthur Benton's enduring influence 60 years later. J Clin Exp Neuropsychol 31: 158169.

30. Perez-Alvarez F, Timoneda-Gallart C (2007) A better look at intelligent behavior. Hauppauge, NY: Nova Science Publishers. 
31. Perez-Alvarez F, Perez-Serra A, Timoneda-Gallart C (2013) A better look at learning: How does the brain express the mind? Psychology 4: 760-770.

32. Pérez-Álvarez F, Timoneda-Gallart C (2014) Intelligent behavior and neuroscience: What we know-and don't know-about how we think. In: Papadopoulos TC, Parrila RK, Kirby JR, (eds). Cognition, intelligence, and achievement: A Tribute to J. P. Das. NY: Elsevier Inc.

33. Das JP, Naglieri JA, Kirby JR (1994) Assessment of cognitive processes. The PASS theory of intelligence. Massachussets: Allyn \& Bacon, Inc.

34. Das JP, Kar R, Parrila RK (1996) Cognitive planning. The psychological basis of intelligent behavior. London: Sage Publications Ltd.

35. Naglieri JA, Das JP (1997) Cognitive Assessment System. Illinois: Riverside Publishing.

36. Das JP (1999) A neo-Lurian approach to assessment and remediation. Neuropsychol Rev 9: 107-115.

37. Perez-Alvarez F, Timoneda-Gallart C (2004) Learning both in attention deficit disorder and dyslexia in the light of pass neurocognitive dysfunction. In: Tobias HD, Editor. Focus on dyslexia research. Hauppauge, NY: Nova Science Publishers, Inc 173-179.

38. Perez-Alvarez F, Timoneda-Gallart C (2005) Attention deficit/ hyperactive disorder as impulsivity disorder according to PASS neurocognitive function. In: P. Larimer P (ed). Attention deficit hyperactivity disorder research developments. Hauppauge, NY: Nova Science Publishers, Inc 173-184.

39. Perez-Alvarez F, Timoneda-Gallart C (2007) Assessment of cognitive processes: The basis of intelligent behavior. In: M. A Lange MA, Editor. Leading-edge psychological tests and testing. Hauppauge, NY: Nova Science Publishers, Inc 10-25.

40. Perez-Alvarez F, Serra-Amaya C, Timoneda-Gallart C (2009) Cognitive versus behavioral ADHD phenotype: what is it all about? Neuropediatrics 40: 32-38.

41. Gazzaniga M (2007) My brain made me do it. In: Glannon W, (ed). Defining right and wrong, in brain science. New York, Washington, DC: Dana Press 1198-2011.

42. Libet B, Gleason CA, Wright EW, Paul DK (1983) Time of conscious intention to act in relation to onset of cerebral activity (readiness potential). The unconscious initiation of a free voluntary act. Brain 106: 623-642.

43. Haggard P, Libet B (2001) Conscious intention and brain activity. Journal of Consciousness Studies 8: 47-64.

44. Graziano M, Polosecki P, Shalom DE, Sigman M (2011) Parsing a perceptual decision into a sequence of moments of thought. Front Integr Neurosci 5: 45.

45. Serra-Sala M, Timoneda-Gallart C, Pérez-Álvarez F (2012) Evaluating prefrontal activation and its relationship with cognitive and emotional processes by means of hemoencephalography (HEG). J Neurotherapy 16: 183-195.

46. LeDoux JE (1996) The emotional brain. New York: Simon \& Schuster; 1996.

47. Carmen JA (2008) Passive infrared hemoencephalography: four years and 100 migraines. J Neurother 8: 23-51.

48. Toomim H, Carmen J (2009) Hemoencephalography: photonbased blood flow neurofeedback. In: Budzinsky TH, Budzinsky HK, Evans JR, Abarbanel A, (eds). Introduction to quantitative
EEG and neurofeedback. Advanced theory and applications. (2ndedn). New York, NY: Academic Press pp: 169-194.

49. Rueda MR, Checa P, Cómbita LM (2012) Enhanced efficiency of the executive attention network after training in preschool children: immediate and after two months effects. Dev Cogn Neurosci 2: S192-S204.

50. Eriksen CW, Pollack MD, Montague W (1970) Implicit speech: Mechanism in perceptual encoding? J Exp Psychol Hum Percept Perform 84: 502-507.

51. Peretz I, Gagnon L, Bouchard B (1998) Music and emotion: perceptual determinants, immediacy, and isolation alter brain damage. Cognition 68: 11141.

52. Blood AJ, Zatorre RJ, Bermudez P, Evans AC (1999) Emotional responses to pleasant and unpleasant music correlate with activity in paralimbic brain regions. Nat Neurosci 2: 3827.

53. Blood AJ, Zatorre RJ (2001) Intensely pleasurable responses to music correlate with activity in brain regions implicated in reward and emotion. Proc Natl Acad Sci USA 98: 11818-11823.

54. Zatorre RJ, Peretz I (2001) The biological foundations of music. Ann NY Acad Sci 930.

55. Trainor LJ, Schmidt LA (2003) Processing emotions induced by music. In: Peretz I, Zatorre, RJ, (eds). The cognitive neuroscience of music. New York: Oxford University Press pp: 31024.

56. Grewe O, Nagel F, Kopiez R, Altenmüller E (2005) How does music arouse "chills"? Investigating strong emotions, combining psychological, physiological, and psychoacoustical methods. Ann N Y Acad Sci 1060: 446-449.

57. Gosselin N, Peretz I, Johnsen E, Adolphs R (2007) Amygdala damage impairs emotion recognition from music. Neuropsychologia 45: 23644

58. Mizuno T, Sugishita M (2007) Neural correlates underlying perception of tonality related emotional components. Neuroreport 18: 16515.

59. Frith U, Frith CD (2003) Development and neurophysiology of mentalizing. Philos Trans R Soc Lond B Biol Sci 358: 459.

60. Blair C, Diamond A (2008) Biological processes in prevention and intervention: the promotion of self-regulation as a means of preventing school failure. Dev Psychopathol 20: 899-911.

61. Smetana JG (1981) Preschool children's conceptions of moral and social rules. Child Development 52: 1333-1336.

62. Buschkuehl M, Jaeggi SM, Jonides J (2012) Neuronal effects following working memory training. Dev Cogn Neurosci 2: S167S179.

63. Kepecs A, Mainen ZF (2012) A computational framework for the study of confidence in humans and animals. Philos Trans $R$ Soc Lond B Biol Sci 367: 1338-1349.

64. Stevens C, Bavelier D (2012) The role of selective attention on academic foundations: a cognitive neuroscience perspective. Dev Cogn Neurosci 2: S30-S48.

65. Roderer T, Roebers CM (2010) Explicit and implicit confidence judgments and developmental differences in metamemory: An eye-tracking approach. Metacogn Learn 5: 229-250.

66. Sander MC, Werkle-Bergner $M$, Gerjets $P$, Shing $Y L$, Lindenberger $U$ (2012) The two-component model of memory development, and its potential implications for educational settings. Dev Cogn Neurosci 2: S67-S77. 
67. Ridderinkhof KR, Van den Wildenberg WP, Segalowitz SJ, Carter CS (2004) Neurocognitive mechanisms of cognitive control: The role of prefrontal cortex in action selection, response inhibition, performance monitoring, and reward-based learning. Brain Cogn 56: 129-140.

68. Van den Bos W, Crone EA, Guroglu B (2012) Brain function during probabilistic learning in relation to $I Q$ and level of education. Dev Cogn Neurosci 2: S78-S89.

69. Timoneda-Gallart C (2006) La experiencia de aprender. Girona: CCG (eds).

70. Mayoral-Rodriguez S (2002) Diagnosis and intervention in students of secondary education with problems of aggression: A proposal for the improvement of educational psychology procedure.

71. González-Castro P, Cueli M, Rodríguez C, García T, Alvarez L (2016) Efficacy of neurofeedback versus pharmacological support in subjects with ADHD. Appl Psychophysiol Biofeedback 41: 17-25.

72. Rodríguez C, González-Castro P, Cueli M, Areces D, GonzálezPienda JA (2016) Attention Deficit/Hyperactivity Disorder (ADHD) Diagnosis: An Activation-Executive Model. Front Psychol 7: 1406.

73. Pecyna MB, Pokorski M (2013) Near-infrared hemoencephalography for monitoring blood oxygenation in prefrontal cortical areas in diagnosis and therapy of developmental dyslexia. In: Pokorski M. (ed). Neurobiology of respiration. Advances in Experimental Medicine and Biology. Dordrecht : Springer Science 175-180.

74. Coben R, Padolsky I (2008) Infrared imaging and neurofeedback: Initial reliability and validity. J Neurotherapy 11: 3-13.

75. Carmen JA (2004) Passive infrared hemoencephalography: Four years and 100 migraines. J Neurotherapy 8: 23-51. 